\title{
USO DE VERMICULITA MASSAPÉ PAULISTANA COMO ADSORVEDORA DE METAIS
}

\section{USING MASSAPÉ PAULISTANA VERMICULITE TO ADSORB ELEMENTS OF METALS}

\section{QUEENIE SIU HANG CHUI}

Doutora em Química Analítica Ambiental pelo Instituto de Química da Universidade de São Paulo. Professora Pesquisadora do Programa de Pós-Graduação stricto sensu em Engenharia e Ciência dos Materiais da Universidade São Francisco, Itatiba, SP.

Recebido: 13/05/04 Aceito: 01/10/04

\section{RESUMO}

Testes de saturação foram efetuados em laboratório, utilizando a vermiculita Massapé Paulistana como adsorvente em soluçōes aquosas de $\mathrm{pH}$ 1, 2, 3, 4, 5 contendo os íons bivalentes, $\mathrm{Cd}(\mathrm{II})$, $\mathrm{Ni}(\mathrm{II}), \mathrm{Pb}$ (II), $\mathrm{Hg}$ (II), nas concentraçóes de $6,3 \times 10^{-3}, 12,5 \times 10^{-3} \mathrm{e}$ $25,1 \times 10^{-3}$ mols.dm ${ }^{-3}$ ede $4,2 \times 10^{-3}, 8,4 \times 10^{-3}$ e $16,8 \times 10^{-3}$ mols.dm $^{-3}$ de $\mathrm{Cr}$ (III) em tempos de contato de 10, 30, 60 120, 240, 360 minutos. Verificou-se que 4 horas foram suficientes para atingir o equilíbrio em todos os casos e que a retenção dos íons pela vermiculita era dependente do $\mathrm{pH}$ do meio, com exceção para $\mathrm{Cr}(\mathrm{III})$. Nessas condições foi conduzido um experimento utilizando efluente líquido gerado em laboratório químico. Observou-se que os critérios para níveis de metais tolerados pelos órgãos de fiscalização para o descarte de efluentes em São Paulo foram atendidos.

PALAVRAS-CHAVE: Massapé Paulistana vermiculita, adsorção de metais, testes de saturação.

\begin{abstract}
Experiments with batch tests in laboratory were conducted utilizing Massape Paulistana vermiculite as adsorbent and aqueous solutions containing $6,3 \times 10^{-3}, 12,5 \times 10^{-3}$ and $25,1 \times 10^{-3}$ mols. $^{-3}$ of each of the bivalent cations, $\mathrm{Cd}(\mathrm{II}), \mathrm{Ni}(\mathrm{II}), \mathrm{Pb}(\mathrm{II}), \mathrm{Hg}(\mathrm{II})$, and $4,2 \times 10^{-3}, 8,4 \times 10^{-3}$ e 16,8 $\times 10^{-3}$ mols. dm $^{-3}$ of Cr(III) at $\mathrm{pH}$ conditions of $1,2,3,4,5$ and contact time of 10,30, 60, 120, 240, 360 minutes. It was observed that retention was dependent on $p H$, except for $\mathrm{Cr}$ (III) and that 4 hours were enough to reach equilibrium conditions for all studied cations. At such conditions, an experiment was also conducted using wastewater effluents from a chemical laboratory. Criteria for metal tolerable levels were observed according São Paulo State Regulations for environmental control of wasterwater discharges.
\end{abstract}

KEYWORDS: Massapé Paulistana vermiculite, metals adsorption, batch saturation test.

\section{INTRODUÇÃO}

Em São Paulo, há uma regulamentação (Decreto Estadual, 1976) para o despejo de efluentes na rede de esgotos preparada para conduzi-los a estaçốes de tratamento especialmente dimensionadas para esta finalidade. As diretivas de lei definem padrôes mínimos para a qualidade do tratamento em função dos corpos de águas para os quais estes efluentes pré-tratados serão encaminhados.

Íons de metais representam formas de contaminação de recursos hídricos, cuja qualidade das águas se torna cada vez mais comprometida. O tratamento de efluentes contendo íons de metais envolve processos físico-químicos de precipitação, troca iônica, adsorção e extração por solventes (Tchobanoglous e Burton, 1991). Porém, essas técnicas tradicionais são de baixa eficiência para a separação de grandes volumes de efluentes contendo íons de metais em baixas concentraçôes.
Métodos alternativos como a eletrodiálise, a osmose reversa, a ultrafiltração e a troca iônica vêm sendo empregados. Dentre os trocadores iônicos mais utilizados estão as resinas orgânicas, as zeólitas e as bentonitas Jimenez et al, 2004). Outros tipos de materiais são utilizados em processos similares como os carvôes ativados, argilominerais, géis inorgânicos (Airoldi e Farias, 2000) e aluminas ativadas. Carvões e alumina ativadas não possuem uma rede cristalina ordenada e seus poros não são uniformes. O tamanho e a distribuição aleatória dos poros favorecem a entrada de moléculas orgânicas e inorgânicas, sendo utilizados em processos catalíticos e de polimerização (Tchobanoglous e Burton, 1991). Argilominerais e óxidos de ferro empregados em processos de troca iônica, para a remoção de íons de metais em solução aquosa, têm valores de retenção comparáveis a de outros tipos de materiais como zeólitas e resinas trocadora de íons, como é o caso da sepiolita
(Brigatti et al, 1999), paligorskita e goethita (Garcia-Sanchez et al, 1999; Brown et al, 1995) e bentonita (Triantafyllou et al, 1999).

Estudos realizados mostram que as partículas coloidais das frações de argila, presentes em sedimentos e solos, interagem com os poluidores que entram no meio ambiente através de despejos de efluentes (Reimers e Krenkel, 1974). Experimentos recentes sugerem que as frações de argilas em solos atuam como concentradores de metais. Vários estudos foram desenvolvidos (Raymahashay, 1987; Obukhovskaya, 1982; Farrah e Pickering, 1977; Das e Bandyopadhyay, 1991; Gupta e Sharma, 1994; Pereira et al, 2004), quando se utilizaram argilominerais para o controle da poluição ambiental.

Sabe-se que, entre os argilominerais, as vermiculitas são as que apresentam maior capacidade de troca de cátions, sendo que, em literatura, são dados valores 
na faixa de 100 a 150 miliequivalentes por 100 gramas $(\mathrm{meq} / 100 \mathrm{~g})$ de massa seca (Grim, 1968).

A vermiculita MASSAPÉ PAULISTANA originária da região do sudeste do Estado do Piauí, representando um dos principais depósitos (DNPM, 1996) de vermiculita do Brasil, é um silicato hidratado de alumínio e magnésio que na natureza ocorre como flocos laminados, sendo muito explorada comercialmente (Vieira Coelho, 1986).

A vermiculita faz parte do grupo dos filossilicatos 2:1, em que cada partícula monocristalina é formada pela superposição de um certo número de camadas de estrutura e espessura bem definidas, separadas por intervalos denominados espaços interfoliares (Mathieson, 1958). Cada camada, por sua vez, é composta por duas folhas de tetraedros de $\left(\mathrm{SiO}_{4}\right)^{4-}$, entre as quais se liga uma folha octaédrica de composição brucítica, $\mathrm{Mg}_{3}(\mathrm{OH})_{6}$. O espaço interfoliar é ocupado por cátions hidratados que têm a função de neutralizar as cargas elétricas geradas pelas substituições isomórficas que ocorrem na estrutura do mineral (Grim, 1968). Os cátions interfoliares mais comuns encontrados em vermiculitas naturais são magnésio e cálcio, e podem ser facilmente trocados por potássio, sódio, rubídio, césio, lítio e amônio (Calle e Suquet, 1988).

Considerando as propriedades da vermiculita, esse estudo propóe-se a explorar a utilização desse argilomineral como adsorvedora de íons de metais.

\section{OBJETIVO}

Este trabalho estuda as propriedades de retenção dos elementos $\mathrm{Cd}(\mathrm{II})$, $\mathrm{Ni}(\mathrm{II}), \mathrm{Pb}(\mathrm{II}) \mathrm{Hg}$ (II) e $\mathrm{Cr}$ (III) pela vermiculita Massapé Paulistana tendo em vista o tratamento de efluentes líquidos.

\section{MATERIAIS E MÉTODOS}

A amostra estudada de vermiculita foi obtida após moagem e peneiramento passando tudo em peneira de malha 0,149 mm (ABNT 100).

A vermiculita foi caracterizada quanto à composição química total utilizando as técnicas de Espectrometria de Fluorescência de Raios Xe Absorção Atômica Chama. A área superficial foi determinada pelo método volumétrico BET (ASTM D-3663/92) e a porosidade por injeção de mercúrio (ASTM D4404-92).

Foram realizados testes preliminares de saturação à temperatura ambiente de $21^{\circ} \mathrm{C}$, usando cerca de $1,0 \mathrm{~g}$ de vermiculita como adsorvente e $20 \mathrm{~cm}^{3}$ de soluções aquosas contendo os íons $\mathrm{Cd}(\mathrm{II}), \mathrm{Ni}$ (II), $\mathrm{Pb}$ (II) e $\mathrm{Hg}$ (II) na faixa de concentração de $6,3 \times 10^{-3}, 12,5 \times 10^{-3}$ e $25,1 \times 10^{-3}$ mols. $^{-3}$ e Cr (III) em concentração de $4,2 \times 10^{-3}, 8,4 \times 10^{-3} \mathrm{e}$ $16,8 \times 10^{-3}$ mols. $\mathrm{dm}^{-3}$. As condições de $\mathrm{pH} 1,2,3,4$ e 5 foram ajustadas com a adição de volumes adequados de solução 0,05 mols. dm ${ }^{-3}$ de $\mathrm{HCl}$. Os reagentes químicos utilizados eram de grau analítico $\left(\mathrm{CdCl}_{2} \cdot 2 \mathrm{H}_{2} \mathrm{O} ; \mathrm{NiSO}_{4} \cdot 6 \mathrm{H}_{2} \mathrm{O}\right.$; $\left.\mathrm{PbNO}_{3} ; \mathrm{HgCl}_{2} ; \mathrm{Cr}_{2}\left(\mathrm{SO}_{4}\right)_{3} .9 \mathrm{H}_{2} \mathrm{O}\right)$.

Foram estabelecidos os tempos de contato de 10, 30, 60120,240 e 360 minutos para os ensaios utilizando agitadores com barra magnética em béqueres de $50 \mathrm{~mL}$. Após o tempo estabelecido para cada experimento, a vermiculita foi removida por filtração usando papel de filtro Whatman $\mathrm{n}^{0} \mathbf{4 0}$. A concentração dos íons presentes no líquido remanescente foi determinada empregando a técnica analítica da espectrofotometria de absorção atômica com chama. A quanti- dade de íon do metal retida pela vermiculita, em percentagem, foi calculada usando a expressáo: $\%\left[\mathrm{Me}^{\mathrm{n}+}\right]_{\text {recido }}=\left[1-\left(\mathrm{C}_{\mathrm{e}} / \mathrm{C}_{\mathrm{i}}\right)\right] \times 100$, sendo $\mathrm{C}_{\mathrm{e}}=\mathrm{n}^{\mathrm{o}}$ de mols do íon nas condições de equilíbrio e $\mathrm{C}_{\mathrm{i}}=\mathrm{n}^{\circ}$ de mols iniciais do íon, no início do experimento. Após esses testes, um experimento utilizando efluente proveniente de laboratório químico foi realizado para verificar se os níveis de metais tolerados pelos órgãos de fiscalização, para o descarte de efluentes em São Paulo, eram atendidos.

\section{PARTE EXPERIMENTAL}

\section{Caracterização da amostra estudada de vermiculita massapé paulistana}

A composição química, a área específica, o volume de poros e a capacidade de troca catiônica da amostra estudada de vermiculita, moída e passante em malha de $0,149 \mathrm{~mm}$ (Tyler 100 ou ABNT 100 ), foram determinados e seus resultados estão mostrados na Tabela 1.

Tabela I - Características físico-químicas da amostra de vermiculita Massapé Paulistana

\begin{tabular}{|c|c|}
\hline - Área Específica (1) & $8,4 \mathrm{~m}^{2} / \mathrm{g}$ \\
\hline - Volume de Poros (2) & $0,86 \mathrm{~cm}^{3} / \mathrm{g}$ \\
\hline - Capacidade de troca catiônica (3) & $104 \mathrm{meq} / 100 \mathrm{~g}$ de vermiculita \\
\hline \multicolumn{2}{|l|}{ - Composição química (4) } \\
\hline Perda ao fogo & $14,4 \%$ (calcinação a $\left.1000^{\circ} \mathrm{C}\right)$ \\
\hline Silício total $\left(\mathrm{SiO}_{2}\right)$ & $39,8 \quad \% \quad(\mathrm{FRX})$ \\
\hline Alumínio total $\left(\mathrm{Al}_{2} \mathrm{O}_{3}\right)$ & $10,9 \% \quad(\mathrm{FRX})$ \\
\hline Ferro total $\left(\mathrm{F}_{\mathrm{e} 2} \mathrm{O}_{3}\right)$ & $5,1 \% \quad($ FRX $)$ \\
\hline Titânio total $\left(\mathrm{TiO}_{2}\right)$ & $0,8 \% \quad$ (AAS) \\
\hline Cálcio total $(\mathrm{CaO})$ & $3,4 \% \quad$ (AAS) \\
\hline Magnésio total (MgO) & $24,9 \% \quad(\mathrm{AAS})$ \\
\hline Sódio total $\left(\mathrm{Na}_{2} \mathrm{O}\right)$ & $0,05 \% \quad(\mathrm{FRX})$ \\
\hline Potássio total $\left(\mathrm{K}_{2} 0\right)$ & $0,5 \% \quad(\mathrm{FRX})$ \\
\hline Cromo solúvel $\left(\mathrm{Cr}^{3+}\right)$ & $0,06 \%$ (AAS) \\
\hline Níquel solúvel $\left(\mathrm{Ni}^{2+}\right)$ & $0,02 \% \quad(\mathrm{AAS})$ \\
\hline Zinco solúvel $\left(\mathrm{Zn}^{2+}\right)$ & $0,004 \% \quad(\mathrm{AAS})$ \\
\hline Cobre solúvel $\left(\mathrm{Cu}^{2+}\right)(5)$ & $0,001 \% \quad(\mathrm{AAS})$ \\
\hline
\end{tabular}

(FRX - técnica de espectrometria de fluorescência de Raios X)

(AAS - técnica de espectrofotometria de absorção atômica chama)

(1) método volumétrico BET segundo norma ASTM D-3663/92

(2) porosimetria por injeção de mercúrio baseada na norma ASTM D4404-92

(3) método analítico empregado segundo IAC Boletim Técnico n⿳o 106 (Camargo et al., 1986). As unidades não estão expressas segundo o Sistema Internacional de Unidades; porém permancem para facilitar a comparação com resultados citados em literatura

(4) determinada na amostra seca a $110^{\circ} \mathrm{C}$ (umidade determinada foi de $8,5 \%$ )

(5) em ácido clorídrico $1 \%$. 


\section{Resultados dos testes de saturação}

As Figuras 1 a 5 mostram a \% retida dos íons em função do tempo de contato com a vermiculita Massapé Paulistana em diferentes condiçôes de $\mathrm{pH}$. Em todas as figuras, a relação massa de vermiculita por massa de sal contendo o respectivo íon, indicada como $1: 1,1: 1 / 2,1: 1 / 4$, expressa a relação em miliequivalentes de vermiculita por miliequivalente do sal e corresponde, respectivamente, a concentraçôes de $25,1 \times 10^{-3}, 12,5 \times 10^{-3} \mathrm{e}$ $6,3 \times 10^{-3}$ mols. $\mathrm{dm}^{-3}$, para Cd(II), Ni(II), $\mathrm{Pb}$ (II) eHg(II) e concentraçáo de $16,8 \times 10^{-3}$, $8,4 \times 10^{-3}$ e $4,210^{-3}$ mols.dm ${ }^{-3}$ para $\mathrm{Cr}$ (III).

Foi observado que o tempo mínimo para atingir a concentração de equilíbrio de todos os íons estudados foi de 04 horas.

A Figura 1 apresenta os resultados para o estudo de adsorção com o íon Cd(II).

É verificada, na Figura 1, que a retenção máxima de $94 \%$ foi obtida na relação 1:1/4, em pH 5, correspondendo a $1 \mathrm{~g}$ de vermiculita e $6,3 \times 10^{-3}$ mols. $^{-3}$ de Cd (II), baixando para menos de 65\% para as demais relações adsorvente/adsorbato. Observa-se que a retenção de cádmio pela vermiculita diminui à medida que o $\mathrm{pH}$ diminui, constatando-se que sua resposta é dependente do $\mathrm{pH}$ do meio. A formação de espécies com cargas negativas e a alta mobilidade dos complexos de cloretos de cádmio (Doner, 1978; Farrah e Pickering, 1977; GarciaMiragaya e Page, 1976; Giordano et al, 1983; Hahne e Kroontje, 1973; Lun e Christensen, 1958) representam os principais fatores responsáveis pela baixa retenção da vermiculita, uma vez que o $\mathrm{pH}$ das soluções utilizadas foi controlada com a adição de volumes de solução 0,05 mols. $\mathrm{dm}^{-3}$ de $\mathrm{HCl}$. Estudos confirmam que espécies sem cargas formadas entre íons cloretos e $\mathrm{Cd}$ (II) competem com os sítios de adsorção da vermiculita (Lun e Christensen, 1958; Hahne e Kroontje, 1973; Garcia-Miragaya e Page, 1976).

A Figura 2 mostra os resultados dos testes de saturação para soluçōes contendo íons de $\mathrm{Ni}$ (II).

Observando a Figura 2, verifica-se que a retenção de $\mathrm{Ni}$ (II) também é máxima na relação $1: 1 / 4$, correspondendo a concentrações de $6,3 \times 10^{-3}$ mols. dm $^{-3}$ de íons $\mathrm{Ni}(\mathrm{II})$. Valores acima de $98 \%$ de retenção foram alcançados, abaixando para $90 \%$ na relação $1: 1 / 2$ e caindo por volta de $90 \%$ na relação 1:1, todos os casos em $\mathrm{pH} 5$.

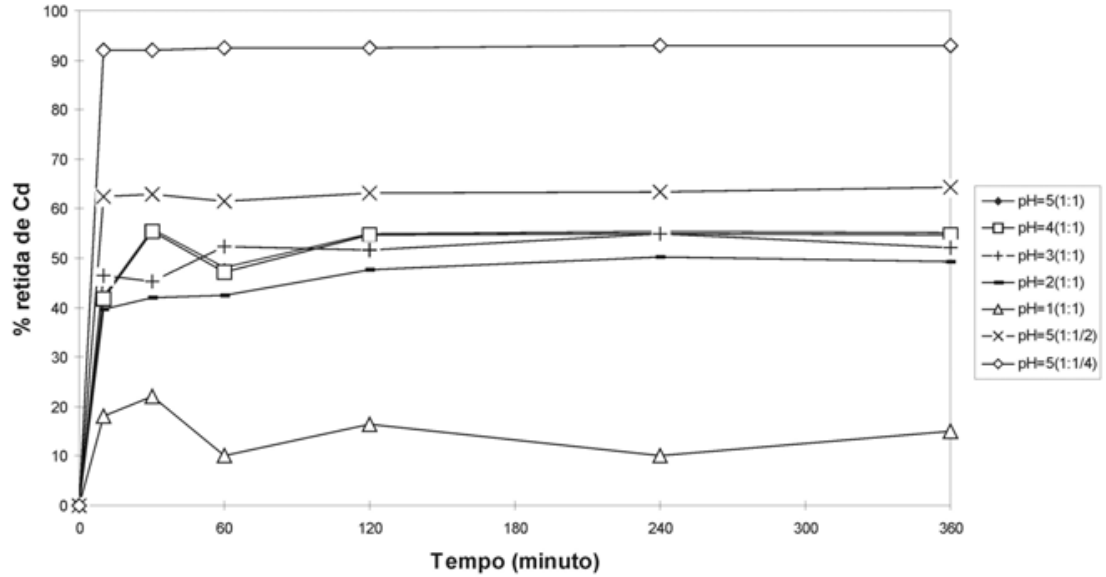

\section{Figura I - Porcentagem retida de $\mathrm{Cd}\left(\mathrm{CdCl}_{2} .2 \mathrm{H}_{2} \mathrm{O}\right)$ em função de tempo (em diferentes condições de $\mathrm{pH}$ e relação de massa)}

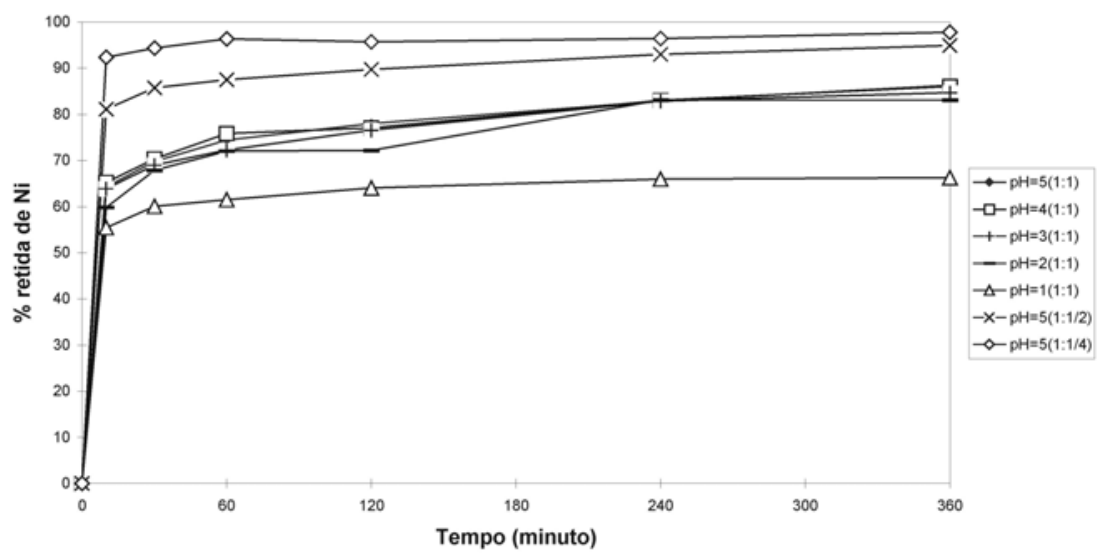

Figura 2 - Porcentagem retida de $\mathrm{Níquel}\left(\mathrm{NiSO}_{4} \cdot 6 \mathrm{H}_{2} \mathrm{O}\right)$ em função de tempo (em diferentes condições de $\mathrm{pH}$ e relação de massa)

Observa-se, também, que para valores de $\mathrm{pH} 2,3 \mathrm{e} 4$, as respostas são muito próximas, somente se distinguindo a resposta para $\mathrm{pH} 1$.

Em seguida é apresentada a Figura 3, que mostra os resultados dos testes de saturação para o íon $\mathrm{Pb}$ (II).

Verifica-se que, para o caso de $\mathrm{Pb}$ (II), as respostas foram muito semelhantes às obtidas para Ni(II). Porém em porcentagem de retenção, para as relaçóes 1:1/4 e 1:1/2 em $\mathrm{pH} 5$, chegou-se a atingir $100 \%$ de retenção. Exceto para $\mathrm{pH} 1$, que apresentou retenção de $50 \%$, para as demais condiçōes de teste em pH 2, 3, 4 e 5, na relação 1:1, a retenção chegou a atingir de 80 a $90 \%$, sendo maior à medida que o $\mathrm{pH}$ se afastava de 2 .

A Figura 4 mostra a resposta do ensaio usando soluções contendo $\mathrm{Hg}(\mathrm{II})$.
A retenção de mercúrio pela vermiculita, quando comparada às respostas obtidas com os demais íons estudados, foi baixa, não ultrapassando $30 \%$. Esse fato pode ser explicado devido à formação de espécies hidrolisadas de mercúrio e espécies sem carga como $\mathrm{HgCl}_{2}$, $\mathrm{Hg}(\mathrm{OH})_{2}$ e $\mathrm{HgOHCl}$ favorecida pelo meio (Farrah e Pickering, 1978). Espécies como $\mathrm{Hg}(\mathrm{OH})_{2}$ predominam em $\mathrm{pH}>4$. Em $\mathrm{pH}<6$, a presença de íons cloretos facilita a formação de espécies como $\mathrm{HgCl}^{+}$e $\mathrm{HgCl}_{2}$. Pode-se dizer que as condiçōes estabelecidas para o desenvolvimento dos ensaios favoreceram a baixa resposta de adsorção de íons mercúrio por esta argila.

A Figura 5 ilustra o estudo da retenção de Cr(III) pela vermiculita. 


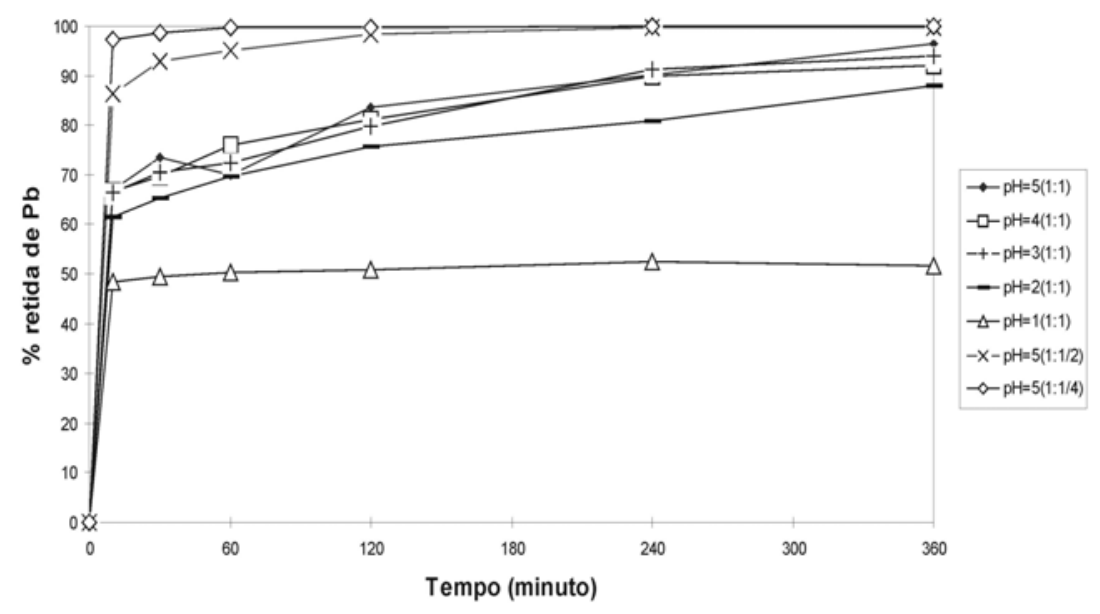

Figura 3 - Porcentagem retida de chumbo $\left((\mathrm{Pb}) \mathrm{NO}_{3}\right)_{2}$ em função de tempo (em diferentes condições de $\mathrm{pH}$ e relação de massa)

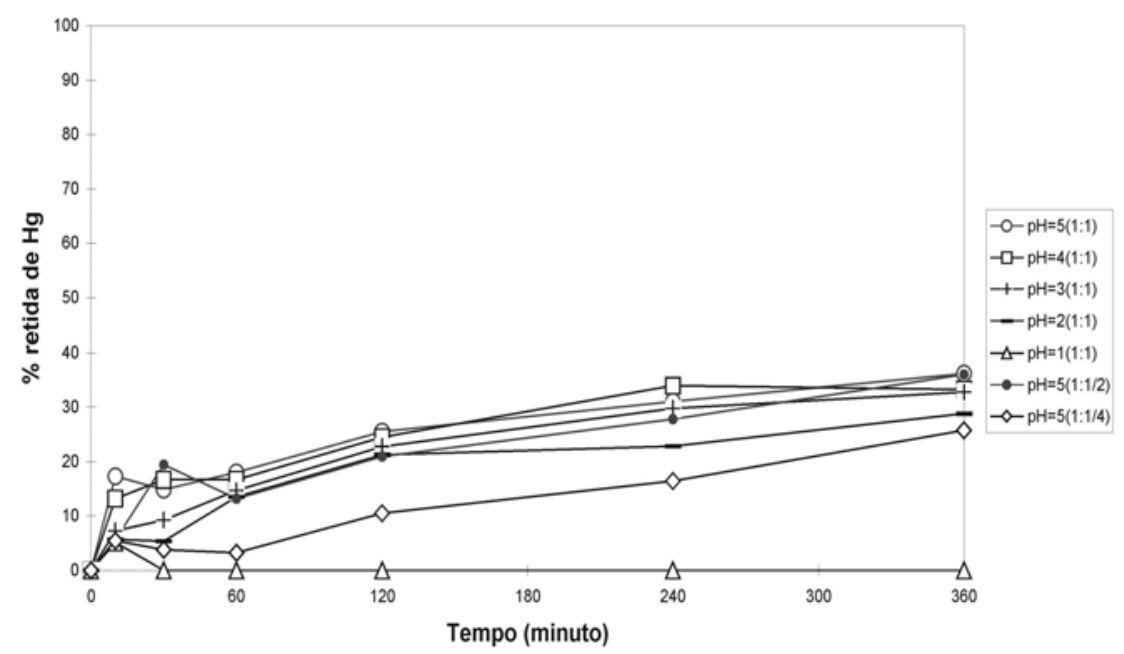

Figura 4 - Porcentagem retida de mercúrio $\left(\mathrm{HgCl}_{2}\right)$ versus tempo (em diferentes condições de $\mathrm{pH}$ e relação de massa)

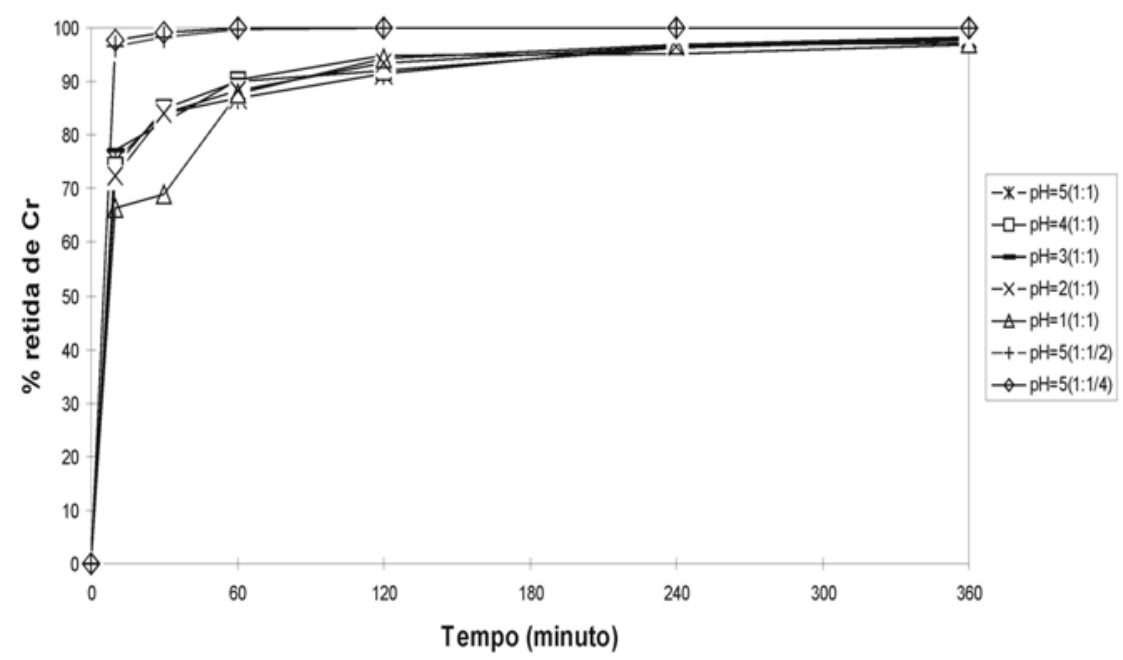

Figura 5 - Porcentagem retida de $\mathrm{Cromo}\left(\mathrm{Cr}\left(\mathrm{NO}_{3}\right)_{3} \cdot 9 \mathrm{H}_{2} \mathrm{O}\right)$ em função de tempo (em diferentes condições de pH e relação de massa)
Observa-se que a retenção de $\mathrm{Cr}(\mathrm{III})$, em todas as condiçóes estabelecidas para os testes de saturação, foram favorecidas. Não se observou a influência de $\mathrm{pH}$, alcançando-se respostas altas de $90 \%$ e acima. No caso da relação $1: 1 / 4$, ou seja, contendo 4 × $10^{-3}$ mols. $\mathrm{dm}^{-3} \mathrm{de} \mathrm{Cr}(\mathrm{III})$, a remoção desse íon foi total.

A vermiculita, após utilizada nos experimentos, foi tratada com solução $1 \mathrm{~mol} . \mathrm{dm}^{-3}$ de $\mathrm{HCl}$, a fim de retirar os íons agregados e promover a regeneração do argilomineral. As soluções ácidas foram analisadas quanto ao teor de íons presentes e verificou-se que foram totalmente recuperadas; a análise por difração de Raios-X da vermiculita após esse tratamento mostrou que a estrutura da mesma foi afetada, o que já era esperado devido à ação agressiva do ácido inorgânico. Podese dizer que o material usado como adsorvente, após separados os íons de metais, não apresenta problemas para ser descartado, ressaltada a necessidade de neutralização da acidez residual. As soluçôes contendo os íons de metais extraídos do adsorvente foram encaminhadas ao tratamento físico-químico convencional.

\section{Experimento com efluente líquido de laboratório químico}

Amostras de efluente líquido gerado durante os trabalhos de rotina do Laboratório de Análises Químicas, da Divisão de Química do Instituto de Pesquisas Tecnológicas do Estado de São Paulo S.A. foram obtidas para esse experimento.

As condições de tratamento do efluente líquido com vermiculita seguiram a descrição mostrada no Quadro 1.

As condições para a realização da etapa 1 foram determinadas tendo como base a relação $1 \mathrm{~g}$ de vermiculita para um volume de $100 \mathrm{~mL}$ de efluente. $\mathrm{Na}$ etapa 2 foi mantida a mesma relação $(0,25 \mathrm{~g}$ vermiculita $/ 25 \mathrm{~mL}$ efluente). Quanto à etapa 3, a amostra de efluente passou por um pré-tratamento com elevação de $\mathrm{pH}$ até 12 com adição de solução de hidróxido de sódio $1 \mathrm{~mol} . \mathrm{dm}^{-3}$, após o qual o material insolúvel foi separado por filtração e a solução remanescente neutralizada com adição de solução de ácido sulfúrico $1 \mathrm{~mol} . \mathrm{dm}^{-3}$ até alcançar valor de $\mathrm{pH}$ por volta de 7 .

Os resultados obtidos para o efluente, antes e depois de tratamento com a vermiculita, estão na Tabela 2 . A determinação dos íons de Cd (II), Cr (III), $\mathrm{Ni}$ (II) e $\mathrm{Pb}$ (II) foi efetuada por espectrofotometria de absorção atômica com chama e leitura direta. 
QUADRO I - CONDIÇÕES DE TRATAMENTO DA AMOSTRA DE EFLUENTE LÍQUIDO COM VERMICULITA MASSAPÉ PAULISTANA

Etapa $1 \quad$ Etapa $2 \quad$ Etapa 3

Efluente coletado Efluente ajustado Efluente pré-tratado $\mathrm{pH} \cong 1$ $\mathrm{p} / \mathrm{pH} 5$ e ajustado $\mathrm{p} / \mathrm{pH} 7$

\begin{tabular}{lccc}
\hline Volume tratado $(\mathrm{mL})$ & 100 & 25 & 100 \\
Massa vermiculita $(\mathrm{g})$ & 1 & 0,25 & 1 \\
Tempo de contato $(\mathrm{h})$ & 4 & 4 & 4 \\
\hline
\end{tabular}

Tabela 2 - Concentração de íons de metais Cd, Ni, Pb e Cr em amostra de efluente líquido antes e após tratamento com vermiculita massapé paulistana

\begin{tabular}{ccccccc}
\hline $\begin{array}{c}{\left[\mathrm{Me}^{\mathrm{n}+}\right]} \\
(\mathrm{mg} / \mathrm{L})\end{array}$ & $\begin{array}{c}\text { Efluente coletado } \\
\mathrm{pH} \cong 1\end{array}$ & $\begin{array}{c}\text { Efluente em } \\
\mathrm{pH} 5\end{array}$ & $\begin{array}{c}\text { Efluente em } \\
\mathrm{pH} \mathrm{7} \\
(\mathrm{a})\end{array}$ & $\begin{array}{c}\text { Limites maximos } \\
\text { (Decreto Estadual, }\end{array}$ & $\begin{array}{c}\text { 1976; art. 18 e 19) } \\
\end{array}$ \\
& $\begin{array}{c}\text { Antes de } \\
\text { tratamento }\end{array}$ & Após & $\begin{array}{c}\text { Após } \\
\text { tratamento }\end{array}$ & $\begin{array}{c}\text { Antes de } \\
\text { tratamento }\end{array}$ & $\begin{array}{c}\text { Após } \\
\text { tratamento tratamento }\end{array}$ & \\
\hline $\mathrm{Cd}$ & 19,6 & 19,0 & 18,4 & 0,5 & $<0,1$ & 0,2 \\
$\mathrm{Cr}$ & 1,7 & 1,5 & $<0,5$ & $<0,5$ & $<0,5$ & 5,0 \\
$\mathrm{Ni}$ & 7,9 & 7,8 & 8,5 & $<1$ & $<1$ & 2,0 \\
$\mathrm{~Pb}$ & 9,9 & 8,2 & 5,8 & 3,0 & $<0,5$ & 0,5 \\
\hline
\end{tabular}

(a) o pH da amostra de efluente foi inicialmente ajustado para 5, condição estabelecida para os testes de saturação (a cor da solução ficou amarelada, possivelmente devido a presença de ferro porém não houve precipitação de sais, após o que foi tratada com vermiculita).

(b) refere-se à amostra de efluente com $\mathrm{pH}$ elevado a 12, seguido de filtração dos insolúveis e ajuste final de $\mathrm{pH}$ para 7 , com nova separação de insolúveis.

O efluente gerado no laboratório químico apresentava um $\mathrm{pH}$ abaixo de 1. Como era esperado, neste $\mathrm{pH}$, a adição de vermiculita não teve efeito na remoção dos metais.

$\mathrm{O} \mathrm{pH}$ do efluente foi ajustado para 5, para estabelecer similaridade de condições conforme testes de saturação efetuados. Nas condições do experimento, ou seja, relação 1:100 (massa vermiculita: volume de efluente), a eficiência para a remoção de metais foi baixa. Para $\mathrm{Pb}(\mathrm{II})$ houve uma redução da ordem de $41 \%\{=[(9,9-5,8): 9,9] \times 100\} ; \operatorname{Cr}(\mathrm{III})$ foi totalmente eliminado; a remoção de $\mathrm{Cd}(\mathrm{II})$ foi de $6 \%$ e não houve efeito sobre $\mathrm{Ni}(\mathrm{II})$. O resultado de $8,5 \mathrm{mg} / \mathrm{L} \mathrm{Ni(II)}$ (Tabela 2), após tratamento em pH 5 , é considerado comparável ao de 7,9 mg/L ( $\mathrm{pH} 1)$, explicável pelas variabilidades da técnica empregada (erros de diluição cometidos nas operações de diluição requeridas). Esses resultados não corresponderam aos esperados e mostrados nos testes de saturação. A formação de complexos de metais eventualmente pre- sente nas condiçóes do experimento, e também devido à matriz complexa do próprio efluente em $\mathrm{pH} 5$, pode ter sido o fator mais importante que impediu a remoção de Cd(II), Ni(II) e Pb(II).

Também foi conduzido o experimento elevando-se o $\mathrm{pH}$ até 12 , com separação dos insolúveis e, após, ajustando o $\mathrm{pH}$ do efluente para 7 , antes de adicionar a vermiculita (este é o valor de $\mathrm{pH}$ que se permite ser lançado o efluente na rede de esgoto, para ser conduzido às estações de tratamento). Observou-se que apenas o ajuste do $\mathrm{pH}$ foi suficiente para separar grande parte dos íons de metais presentes. Após a filtração dos precipitados a vermiculita foi acrescentada ao meio, e após o tempo de contato sob agitação por 04 horas, a solução remanescente foi analisada. O efluente ajustado para $\mathrm{pH} 7$ continha $0,5 \mathrm{mg} / \mathrm{L}$ $\mathrm{Cd}(\mathrm{II})$ e 3,0 mg/L Pb(II) . Após tratamento com vermiculita, resultou em $<0,1 \mathrm{mg} / \mathrm{L}$ $\mathrm{Cd}(\mathrm{II}) \mathrm{e}<0,5 \mathrm{mg} / \mathrm{L} \mathrm{Pb}$ (II). Os níveis residuais atenderam os limites máximos toleráveis, permitindo o lançamento do efluente pré-tratado na rede coletora de esgotos.

\section{CONCLUSÕES}

Os testes de saturação aplicados para o estudo de capacidade de retenção de íons de metais pela vermiculita Massapé Paulistana mostraram-se bastante simples. Não requerem infra-estrutura complexa. Observou-se que $\mathrm{Cr}$ (III), em concentração de 4,2 x $10^{-3}$ mols.dm $^{-3}$, e Pb (II), em concentração de $6,3 \times 10^{-3}$ mols.dm ${ }^{-3}$, ambos em pH 5, foram 100\% retidos. Com exceção para mercúrio, a remoção dos demais elementos em solução mostrou-se promissora, de mais de $90 \%$.

A retenção de mercúrio foi da ordem de 20 a 30\%. Observou-se que a presença de íons cloretos confirmou impedimento para a adsorção de mercúrio pela vermiculita. A formação de espécies hidrolisadas e sem cargas de mercúrio pode ter sido o principal fator responsável pela baixa adsorção de mercúrio. Sendo a poluição ambiental por mercúrio um dos problemas mais sérios não resolvidos, adicionado à elevada probabilidade de se encontrar íons cloretos em alta concentração no meio ambiente, caberia continuar os estudos de adsorção com esse íon em concentrações as mais próximas das encontradas em sistemas reais. Usar uma técnica analítica mais sensível, como é a modalidade de forno de grafite, como atomizador para a espectrofotometria de absorção atômica, ou o do gerador de vapor frio de mercúrio, seria interessante para o estudo de remoção de mercúrio como o adsorbato em concentraçōes mais baixas, o que não foi possível durante a realização do presente estudo.

Como não existem procedimentos padronizados para estudos de adsorção de metais por argilas e argilominerais (Chui e Boscov, 2000), os procedimentos empregados para os testes de saturação, usando a vermiculita como adsorvente de íons Cd(II), Ni(II), Pb(II), Hg (II) e Cr(III), podem ser considerados úteis e fáceis de aplicação, contribuindo para estudos similares usando outras argilas.

Trabalhando com o efluente de laboratório, a análise química das amostras, antes e depois do tratamento com vermiculita, mostrou que a etapa de prétratamento, elevando o $\mathrm{pH}$ acima de 12, prevê a separação de grande parte dos cátions, que são precipitados como hidróxidos insolúveis. Em seguida, abaixando o $\mathrm{pH}$ para 7 , observou-se que $\mathrm{Zn}$ (II) e $\mathrm{Al}(\mathrm{III})$ presentes, que haviam permanecidos em solução como aluminatos e zincatos solúveis, são precipitados, que, por sua vez, foram filtrados. 
O tratamento com a vermiculita Massapé Paulistana permitiu a remoção total de $\mathrm{Cd}$ (II) e $\mathrm{Pb}$ (II) remanescentes.

Os resultados são promissores e indicam uma grande possibilidade de aproveitamento desse argilomineral no tratamento de efluentes. Este trabalho não contemplou o efeito da presença de matéria orgânica. Sabe-se que há a formação de complexos estáveis com os íons de metais e estes podem manter-se em solução sujeitos à transformação pela atividade microbiana presente em ambientes naturais. No entanto, os resultados sugerem ser possível a remoção de metais poluentes presentes em fases aquosas pela vermiculita Massapé Paulistana, podendo a mesma servir de modelo para estudos e estabelecimento de parâmetros de adsorção de metais por argilas.

\section{AGRADECIMENTOS}

Ao Instituto de Pesquisas Tecnológicas pela infra-estrutura laboratorial utilizada e pela oportunidade dada para o desenvolvimento dessa pesquisa.

\section{REFERÊNCIAS}

AIROLDI, C.; FARIAS, R.F; $O$ Uso de Sílica Gel Organofuncionalizada como Agente Sequestrante para Metais. Química Nova, v. 23, n. 4, p.496503, 2000.

ASTM/AMERICAN SOCIETY FOR TESTING MATERIALS, "Standard Test Methods for Surface Area of Catalysts", ASTM $\mathrm{D}-3663 / 1992$.

ASTM/AMERICAN SOCIETY FOR TESTING MATERIALS, "Standard Test Methods for Determining Pore Volume Distribuition of Catalysts by Mercury Injection Porosimetry", ASTM D - 4404 /1992.

BRIGATTI, M.F. et al. Treatment of industrial wastewater using zeolitite and sepiolite, natural microporous materials. Canadian Journal Chemical Engeneering, v. 77, p.163-168, 1999.

BROWN, G. E.; PARKS, G. A.; O'DAY, P A.; Sorption of minerals-water interfaces:macroscopic and microscopic perspective. In: MINERAL SURFACES, D. J. Vaughan \& R. A. D., Pattrick Chapman \& Hall, p.138-147. 1995.

CALLE, C. de la; SUQUET, H.; Vermiculitereviews in mineralogy-hydrous phyllossilicates. Mineralogical Society of America, v. 19, p.455496, 1988.

CAMARGO, et al. Métodos de Análise Quimica, Mineralógica e Física de Solos do Instituto Agronômico de Campinas - Boletim Técnico no 106, Instituto Agronômico, Campinas, 94p. 1986.

CHUI, Q.S.H. ; BOSCOV, M.E.G.; $A$ study of adsorption of metals by a Brazilian Vermiculite for Geo-Environmental Applications. In: GEOENG2000 AN INTERNATIONAL CONFERENCE ON GEOTECHNICAL
AND GEOLOGICAL ENGINEERING, Melbourne, Austrália, Anais em meio digital, v.1. 2000 .

DAS, N.C. and BANDYOPADHYAY, M.; Removal of lead by vermiculite medium. Applied Clay Science, v. 6, $\mathrm{n}^{0}$ 3, p.221-231, 1991.

DECRETO ESTADUAL ${ }^{0} 8468,1976$, regulamento da Lei $\mathrm{n}^{0} 997 / 76$, artigo 18 e 19 , sobre prevenção e controle da poluição do meio ambiente no Estado de São Paulo.

DNPM/DEPARTAMENTO NACIONAL DE PRODUÇÃO MINERAL, Ministério de Minas e Energia, Secretaria de Minas e Metalurgia, República Federativa do Brasil; Anuário Mineral Brasileiro, Vermiculita e Perlita, ref. 440 a $443,1996$.

DONER, H.; Chloride as a factor in mobilities of Ni(II), Cu(II) and Cd(II) in soil. Soil Sci. Soc. Am. Journal, v. 42, p.882-885, 1978.

FARRAH, H. and PICKERING, W.F.; Influence of clay-solute interactions on aqueous heavy metal ion levels. Water, Air and Soil Pollution, v.8, p.189-197, 1977.

FARRAH, H. and PICKERING, W.F.; The sorption of mercury species by clay minerals. Water, Air and Soil Pollution, v. 9, $\mathrm{n}^{0} 1$, p.23-31, 1978.

GARCIA-MIRAGAYA, J. and PAGE, A.L.; Influence of ionic strenght and inorganic complex formation on the sorption of trace amounts of $C d$ by montmorillonite. Soil Sci. Soc. Am. J., v. 40, p.658-663, 1976.

GARCIA-SANCHEZ A.; ALASTUEY, A.; QUEROL, X.; Heavy metal adsorption by different minerals: application to the remediation of polluted soils. Sci. Tot. Environ., v. 242, $\mathrm{n}^{0} 1$ 3, p.179-188, 1999.

GIORDANO, P.M. et al. Mobility in soil and plant availability of metals derived from incinerated municipal refuse. Environm. Sci. Technol., v.17, $\mathrm{n}^{\circ} 4, \mathrm{p} .193-198,1983$.

GRIM, R.F.; Clay Mineralogy, $2^{\text {nd }}$ Edition, New York, McGraw Hill Book Company, 596p. 1968.

GUPTA, G.S. and SHARMA Y.C.; Environmental management of textile and metallic industrial effluents. Journal of Colloid and Interface Science, v. 168, p.118-124, 1994.

HAHNE, H.C.H. and KROONTJE, W.; Significance of $\mathrm{pH}$ and chloride concentration on behavior of heavy metal pollutants : Mercury(II), Cadmium(II), Zinc(II) and Lead(II). Journal of Environmental Quality, v.2, p.444- 450, 1973.

JIMENEZ, R.S.; BOSCO, S.M.D.; CARVALHO, W.A.; Remoção de metais pesados de efluentes aquosos pela zeólita natural escolecita Influência da temperatura e do $\mathrm{pH}$ na adsorção em sistemas monoelementares. Química Nova, v. 27, $\mathrm{n}^{0}$ 5, p.734-738, 2004.

LUN, X.Z. and CHRISTENSEN, T.H.; Cadmium complexation by solid waste leachates. Wat. Res., v.23, n ${ }^{0} 1$, p.81-84, 1989.

MATHIESON, A.M.; Structure of $\mathrm{Mg}$ vermiculite. The American Mineralogist, v.43, p.216-227, 1958.
OBUKHOVSKAYA, T.D.; Mercury sorption by soil minerals. Soviet Soil Science, v. 14, $\mathrm{n}^{0} 3$, p.49-55, 1982.

PEREIRA, W.C.; SANTOS, R.; VILLAS BOAS, R.C.; Calcário Dolomítico e Argilomineral, como Vermiculita e sua Utilização como Sorvente de Elementos Potencialmente Contaminantes. Revista Metalurgia e Materiais, v. 60 , n. 54 , jan/fev. 2004 .

RAYMAHASHAY, B.C.; A comparative study of clay minerals for pollution control. Journal Geological Society of India, v. 30, $n^{0} 5$, p.405413, 1987.

REIMERS, R.S. and KRENKEL, P.A.; Kinetics of mercury adsorption and desorption in sediments. J. Water Pollution Control Federation, v. 46, $\mathrm{n}^{0} 2$, p.352-365, 1974.

TCHOBANOGLOUS, G. and BURTON, F.L. (rev), Wastewater Engineering:Treatment, Disposal and Reuse, $3^{\text {th }}$ Edition. New York, McGraw Hill Book Company, 1334p. 1991.

TRIANTAFYLLOU, S.; CHISTODOULOU, E.; NEOU-SYNGOUNA, P.; Removal of nickel and cobalt from aqueous solution by $\mathrm{Na}$-activated bentonite. Clays and Clay Minerals, v. 47, $\mathrm{n}^{0}$ 5, p.567-572, 1999.

VIEIRA COELHO, A.C. ; Estudo, em escala de laboratório, do inchamento em água de vermiculitas brasileiras tratadas com soluçôes salinas inorgânicas. (Dissertação de Mestrado). Escola Politécnica da Universidade de São Paulo, 244p., 1986.

\section{Endereço para correspondência:}

\author{
Queenie Siu Hang Chui \\ Programa de Pós-Graduação \\ Universidade São Francisco \\ Rua Alexandre Rodrigues Barbosa, 45 \\ I 325 | -900 Itatiba - SP - Brasil \\ Tel.: (I I) 4534-8025 \\ Fax: (I I) 4524- 1933 \\ E-mail:queenie.hang@saofrancisco.ectu.br
}

